\title{
PENYELENGGARAAN SISTEM KREDIT SEMESTER DI SMA NEGERI 2 KOTA BLITAR
}

\author{
Arie Fuat Wijaya, Sulton, Susilaningsih \\ Jurusan Teknologi Pendidikan, Fakultas Ilmu Pendidikan, Universitas Negeri Malang \\ Jalan Semarang 5 Malang 65145-0341-5747001 \\ Email:ariefuat@gmail.com
}

\begin{abstract}
Article History
Received: July, $2^{\text {nd }} 2019$

Accepted: August, $26^{\text {th }} 2019$

Published: August, $31^{\text {st }}$

2019

\section{Keywords}

SKS, Penyelenggaraan Sistem, Beban Belajar, Kecepatan Belajar, Minat, Bakat

Abstrak

Tujuan Penelitian ini adalah untuk mendiskripsikan penyelenggaraan sistem kredit semester di SMA Negeri 2 Blitar. Fokus penelitian terkait dengan : 1) persyaratan, 2) komponen beban belajar, 3) penetapan beban belajar, 4) penentuan beban belajar, 5) pembagian komposisi beban belajar, 6) kriteria pengambilan beban belajar, 7) penilaian, penentuan IP (Indeks Prestasi), dan kelulusan. Analisis data penelitian menggunakan reduksi data yang kemudian dilakukan penyajian data lalu ditarik kesimpulan dan verifikasi. Hasil penelitian secara umum SMA Negeri 2 Blitar menyelenggarakan sistem kredit semester sesuai dengan panduan penyelenggaraan. Hal ini dibuktikan dengan : 1) persyaratan penyelenggaraan berupa dukungan internal dan eksternal, 2) komponen beban yang berisi kegiatan tatap muka, penugasan terstruktur dan kegiatan mandiri, 3) penentapan satuan beban belajar dengan istilah jam pelajaran setiap 45 menit dengan presentase UKBM maksimal 60\% dari kegiatan tatap muka, 4) penentuan beban belajar oleh kemampuan siswa, 5) pembagian komposisi belajar menjadi tiga kelompok, 6) kriteria pengambilan beban belajar setiap minggunya $42 \mathrm{JP}$ pada kelas X, $44 \mathrm{JP}$ pada kelas XI dan 44 JP pada kelas XII, 7) penilaian, penentuan IP dan kelulusan sesuai pada panduan penyelenggarakan SKS di SMA Negeri 2 Blitar.
\end{abstract}

\begin{abstract}
The purpose of this study is to describe the implementation of the semester credit system in Blitar 2 Public High School. The focus of the study relates to: 1) requirements, 2) learning burden, 3) learning burden, 4) learning burden, 5) sharing of learning burdens, 6) examination of calculating learning burden, 7) examinations, determination of IP (Indeks Prestasi), and graduation. Analysis of research data using data reduction which is then performed by presenting data and drawing conclusions and verification. The general results of the Public High School 2 Blitar provide a semester credit system in accordance with the implementation guidelines. This is evidenced by: 1) the implementation requirements consist of internal and external support, 2) cost components that provide face-to-face activities, structured assignments and independent activities, 3) determination of learning units with lessons every 45 minutes with UKBM percentage up to $60 \%$ of activities face to face, 4) learning load management by students' ability, 5) composition of learning composition into three groups, 6) criteria for learning preparation each week $42 \mathrm{JP}$ in class X, $44 \mathrm{JP}$ in class XI and $44 \mathrm{JP}$ in class XII, 7) Assessing, determine the IP and graduation in accordance with the guidance of the SKS organizer at Blitar 2 Public High School.
\end{abstract}




\section{PENDAHULUAN}

Pendidikan merupakan sebuah proses pembelajaran agar mampu berubah baik berupa pengetahuan, sikap dan perilaku. Seperti yang dinyatakan Gagne (dalam Sujiono, 2010:21) bahwa belajar adalah perubahan yang relative permanen dalam perilaku yang terjadi sebagai hasil latihan atau pengalaman dan merupakan suatu proses. Sukmadinata (dalam Muhammedi, 2016: 49) Kurikulum ialah bagian terpenting dari proses pendidikan. Kurikulum adalah salah satu faktor yang paling langsung berpengaruh terhadap hasil pendidikan.

Menurut So \& Kang (dalam Retnawati, dkk 2013) salah satu bukti nyata adalah perubahan kurikulum termasuk konten pendidikan, proses pembelajaran dan penilaian. Perubahan kurikulum semacam itu telah terjadi di wilayah lain seperti Korea. Hal ini selaras dengan Undang-Undang Republik Indonesia Nomor 20 tahun 2003 (dalam Apriliani \& Suwanda, 2019:211) tentang Sistem Pendidikan Nasional pada pasal 1 ayat 1 menjelaskan bahwa Pendidikan adalah usaha sadar dan terencana untuk mewujudkan susasana belajar dan proses pembelajaran agar peserta didik secara aktif mengembangkan potensi dirinya untuk memiliki kekuatan spiritual keagamaan, pengendalian diri, kepribadian, kecerdasan, akhlak mulia, serta keterampilan yang diperlukan dirinya, masyarakat, bangsa dan negara. Melalui proses pembelajaran seseorang akan secara aktif mengembangkan potensi diri yang diperlukan dalam kehidupan berbangsa dan bernegara.

Menurut Widyastono (2013:606) terdapat dua cara menghadapi anak dengan kecerdasan istimewa, yaitu dengan program percepatan dan program pengayaan. Penelitian mengenai implementasi SKS pernah dilakukan oleh Pertiwi (2015). Dari penelitian tersebut diperoleh hasil bawha proses pembelajaran telah berpusat pada peserta didik, sehinnga lebih mengutamakan siswa dalam belajar bukan guru. Sedangkan penelitian dari Muhlis (2011) tentang pengembangan pembelajaran dengan menggunakan SKS megatakan bahwa SKS dapat memberikan pelayanan terhadap peserta didik dengan cara yang lebih bervariatif dan fleksibel sesuai dengan kemampuan, bakat, dan minat. Dalam pengembangan pembelajaran dengan menggunakan SKS, peserta didik dapat belajar dengan motivasi tinggi, memiliki kemandirian, dan sesuai dengan potensinya. Di antara semua persyaratan lain untuk implementasi kurikulum, guru harus terus dipantau dan didukung untuk meningkatkan kualitas pengajaran dan pembelajaran (Makeleni \& Sethusa, 2014)

Dalam memenuhi pelayanan pendidikan yang adil sesuai dengan kententuan diatas maka pemerintah menerapkan Sistem Kredit Semester (SKS) sebagaimana telah diatur dalam Peraturan Pemerintah No. 19 Tahun 2005 (dalam Wahid, 2016:23) tentang Standar Nasional Pendidikan pada pasal 11 ayat 2 yang menyatakan "Beban belajar untuk SMA/MA/SMLB, SMK/MAK atau bentuk lain yang sederajat pada jalur pendidikan formal kategori standar dapat dinyatakan dalam satuan kredit semester" dan ayat 3 yang menyatakan "Beban belajar untuk SMA/MA/SMLB, SMK/MAK atau bentuk lain yang sederajat pada jalur pendidikan formal kategori mandiri dinyatakan dalam satuan kredit semester".

Penelitian ini bertempat di SMA Negeri 2 Blitar. Peneliti memilih SMA Negeri 2 Blitar karena SMA tersebut merupakan Sekolah Menengah Atas di Kota Blitar yang pertama melaksanakan Sistem Kredit Semester yang telah menerapkan SKS sejak tahun ajaran 2015/2016. SMA Negeri 2 termasuk sekolah yang menggunakan SKS-B. Kebijakan ini bersamaan dengan berlakunya kurikulum 2013 yang sebelumnya memakai Kurikulum Tingkat Satuan Pendidikan. Hal ini sesuai dengan pernyataan Kementerian Pendidikan dan Kebudayaan (dalam Muhamad \& Saparahayuningsih, 2016:269) pemerintah menyambut desakan dengan menuangkan target utama dalam kurikulum 2013, yaitu pembentukan sikap dan karakter generasi muda. Faktor terpenting dalam implementasi kurikulum 2013 adalah kesiapan pelaksana kurikulum itu sendiri. Tidak peduli seberapa bagus kurikulum yang 
digunakan, itu tergantung pada kesiapan guru untuk mengimplementasikannya (Febriya \& Nuryono, 2014).

Hal inilah yang mendasari peneliti untuk melakukan penelitian tentang penyelenggaraan sistem kredit semester yang dilakukan di SMAN 2 Blitar. Penelitian ini bertujuan untuk mendiskripsikan penyelenggaraan sistem kredit semester di SMA Negeri 2 Blitar, meliputi : (1) persyaratan, (2) komponen beban belajar, (3) penetapan beban belajar, (4) penentuan beban belajar, (5) pembagian komposisi beban belajar, (6) kriteria pengambilan beban belajar, (7) penilaian, penentuan IP (Indeks Prestasi), dan kelulusan.

\section{METODE}

Penelitian ini menggunakan metode penelitian kualitatif karena dalam penelitian ini peneliti melakukan pengamatan yang mendalam terhadap obyek yang diteliti bersumber data observasi, wawancara serta dokumentasi. William Wiersman (1986) dalam Sugiyono menyatakan bahwa triangulasi dalam pengujian kredibilitas ini diartikan sebagai pengecekan data dari berbagai sumber dengan berbagai cara, dan berbagai waktu. Dengan demikian terdapat triangulasi sumber, triangulasi teknik pengumpulan data, dan waktu. Sesuai dengan sumber data dan teknik pengumpulan datanya maka pengecekan data dilakukan dengan triangulasi sumber dan triangulasi teknik pengumpulan data. Model analisis data triangulasi sehingga menghasilkan data yang dapat dideskripsikan menjadi hasil penelitian.

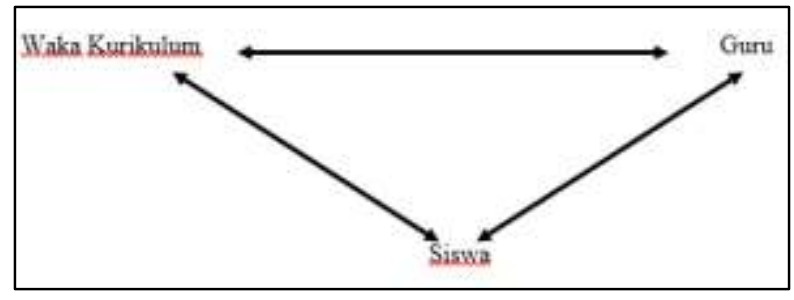

Gambar 1 : Analisis triangulasi sumber

Triangulasi sumber dilakukan dengan mengecek data yang telah diperoleh melalui beberapa sumber. Sumber tersebut yaitu kepala sekolah, waka kurikulum, guru dan siswa. Hasil analisis data yang telah dilakukan oleh peneliti kemudian dimintakan kesepakatan (member check) kepada sumber tersebut.

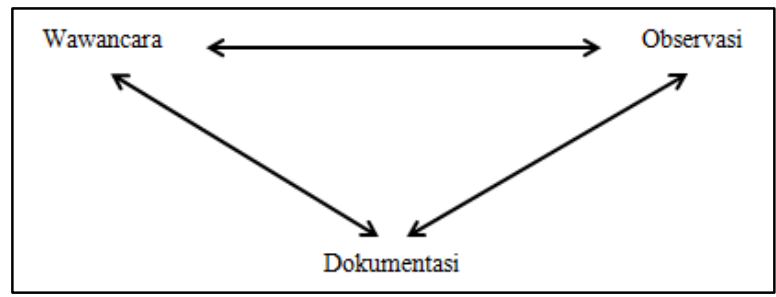

Gambar 2 : Analisis triangulasi teknik

Teknik triangulasi dilakukan dengan cara mengecek data kepada sumber yang sama dengan teknik yang berbeda. Triangulasi teknik yang dilakukan dalam penelitian ini yaitu data yang diperoleh dari hasil wawancara dicek dengan teknik observasi maupun dokumentasi dan data yang diperoleh dari studi dokumentasi dicek dengan observasi maupun wawancara.

Penelitian ini mempunyai tiga tahap, pertama tahap pra lapangan yang memuat langkah menyusun kerangka penelitian, memilih lapangan penelitian, mengurus perijinan, menjajaki dan menilai lapangan, memilih dan memanfaatkan informan, serta menyiapkan kegiatan penelitian. 
Tahap kedua yaitu tahap pelaksanaan memuat tentang penyerahan perijinan, dan pengumpulan data penelitian. Pengumpulan data dilakukan peneliti dengan wawancara, dokumentasi dan observasi. Tahap ketiga yaitu penyusunan laporan dari data yang diperoleh sehingga dapat dideskripsikan menjadi kesimpulan penelitian.

\section{HASIL}

\section{Persyaratan penyelenggaraan Sistem Kredit Semester (SKS) di SMA Negeri 2 Blitar}

SMA Negeri 2 Blitar mendapatkan dukungan internal berupa kinerja sekolah indikator terakreditasi A, yaitu mencapai rerata nilai Ujian Nasional (UN) tiga tahun terakhir lebih dari 7.00, persentase kelulusan Ujian Nasional 100\% untuk tiga tahun terakhir, animo tiga tahun terakhir lebih dari daya tampung sekolah, terdapat prestasi akademik dan non akademik yang diraih, melaksanakan manajemen berbasis sekolah, rata-rata jumlah siswa per kelas 36 orang, ada pertemuan rutin pimpinan dengan guru serta ada pertemuan rutin sekolah dengan orang tua tentang pelaksanaan pembelajaran.

Kurikulum di SMA Negeri 2 Blitar memenuhi sebagai Sekolah Kategori Mandiri, dengan indikator memiliki kurikulum Sekolah Kategori Mandiri, beban studi dinyatakan dengan jam pelajaran, mata pelajaran sesuai dengan jurusan pada awal masuk, panduan/dokumen penyelenggaraan, memiliki pedoman pembelajaran, tidak memiliki pedoman pemilihan mata pelajaran karena sudah ditentukan di awal masuk sesuai jurusan, memiliki panduan menjajagi potensi peserta didik dan memiliki pedoman penilaian.

Kesiapan sekolah juga termasuk dalam SKM, dengan indikator sekolah menyatakan bersedia melaksanakan Sistem Kredit Semester, Persentase guru yang menyatakan ingin melaksanakan SKS 95\%, Pernyataan staf administrasi akademik bersedia melaksanakan SKS, Kemampuan staf administrasi akademik mahir dalam menggunakan komputer.

Sumber daya manusia SMA Negeri 2 memenuhi sebagai Sekolah Kategori Mandiri, dengan indikator persentase guru memenuhi kualifikasi akademik adalah $90 \%$, relevansi guru setiap mata pelajaran dengan latar belakang pendidikan yaitu $100 \%$, rasio antara guru dan siswa seimbang yaitu 1:1 , jumlah tenaga administrasi akademik memadai, tersedia guru bimbingan konseling/ karir.

Fasilitas di sekolah, dengan indikator memiliki ruang kepala Sekolah, ruang wakil kepala sekolah, ruang guru, ruang bimbingan, ruang Unit Kesehatan, tempat Olah Raga, tempat ibadah, lapangan bermain, komputer untuk administrasi, memiliki laboratorium: Bahasa, Teknologi informasi/komputer, Fisika, Kimia, Biologi, Perpustakaan yang memiliki koleksi buku setiap mata pelajaran, memberikan Layananan bimbingan karir. Tidak terdapat laboratorium IPS karena tidak efektif dan belum memiliki laboratorium multimedia. Terdapat dukungan eksternal termasuk dari dukungan komite sekolah, orang tua peserta didik, dukungan dari Dinas Pendidikan Kabupaten/Kota, dukungan dari tenaga pendamping pelaksanaan SKS. Tenaga pendamping merupakan tim kurikulum sekolah dan tim kurikulum provinsi.

\section{Komponen beban belajar pada penyelenggaraan SKS di SMAN 2 Blitar}

Penyelenggaraan sistem kredit semester mempunyai beban belajar dengan komponen yaitu kegiatan tatap muka, penugasan terstruktur dan kegiatan mandiri. Kegiatan tatap muka merupakan kegiatan pembelajaran di dalam kelas dengan metode pembagian kelompok. Untuk pertemuan pertama dengan mengajar secara klasikal sehingga dalam beberapa bahasan terlampaui untuk melihat kecepatan belajar siswa. Kemudian siswa dibagi menjadi tiga kelompok belajar, yaitu cepat, sedang dan kurang cepat. Selanjutnya saat pembelajaran di dalam kelas guru secara berkala melayani setiap kelompok. Penugasan terstruktur merupakan tugas-tugas yang harus dikerjakan oleh siswa agar nantinya dijadikan syarat ketika akan ujian. Kemudian kegiatan mandiri merupakan kegiatan yang harus dilakukan siswa 
secara mandiri demi menunjang pembelajaran. Ketika akan melakukan ujian, guru kadang-kadang memberikan tes agar terlihat siswa yang sudah melakukan kegiatan mandiri ataupun belum. Penugasan terstruktur dan kegiatan mandiri tergabung menjadi satu dalam Unit Kegiatan Belajar Mandiri (UKBM).

\section{Penetapan beban belajar pada penyelenggaraan SKS di SMAN 2 Blitar}

Penyebutan istilah satuan beban belajar pada penyelenggaraan sistem kredit semester di SMA Negeri 2 adalah jam pelajaran. Dalam satu jam pelajaran setara dengan jam pelajaran pada sekolah sistem paket yaitu 45 menit. Untuk presentase penugasan dan kegiatan mandiri tidak lebih $60 \%$ dari kegiatan tatap muka.

\section{Penentuan beban belajar maksimal dan minimal pada penyelenggaraan SKS di SMAN 2 Blitar}

Beban belajar tidak terdapat batas maksimal dan minimal kepada siswa, melainkan sudah ketentuan dari pemerintah. Beban belajar tersebut harus dituntaskan siswa sesuai dengan kecepatan belajar siswa. Penentuan penjurusan siswa dilakukan pada awal masuk sekolah. Peralihan lintas jurusan dapat dilakukan ketika siswa sanggup menuntaskan beban belajar yang terlewat sebelumnya.

\section{Pembagian komposisi beban belajar pada penyelenggaraan SKS di SMA Negeri 2 Blitar}

Terdapat tiga kelompok dalam pembagian kelompok beban belajar. Kelompok A terdapat 6 mata pelajaran. Kelompok B terdapat 3 mata pelajaran dan 1 muatan local. Kelompok C dibagi menurut kelasnya masing-masing. Pada kelas X terdapat 6 mata pelajaran terdiri dari 4 mata pelajaran peminatan dan 2 lintas jurusan atau pendalaman minat. Pada kelas XI dan kelas XII terdapat 5 mata pelajaran terdiri 4 mata pelajaran peminatan dan 1 lintas jurusan atau pendalaman minat.

Lintas jurusan adalah mata pelajaran yang berada pada jurusan lain misalnya siswa jurusan IPA ingin mengambil mata pelajaran ekonomi di jurusan IPS. Syarat minimal untuk melakukan lintas jurusan adalah berjumlah 20 siswa. Sementara pendalaman minat adalah program yang bekerjasama dengan kampus agar siswa bisa mengambil mata kuliah yang nantinya ketika siswa tersebut kuliah disana tidak perlu untuk menempuh lagi mata kuliah tersebut.

\section{Kriteria pengambilan beban belajar pada penyelenggaraan SKS di SMA Negeri 2 Blitar}

Pada tingkat kurikulum seluruh mata pelajaran setiap minggunya siswa harus menuntaskan 42 JP untuk kelas X, lalu untuk kelas XI dan XII harus 44 JP. Kriteria pengambilan beban belajar pada setiap mata pelajaran tergantung gurunya masing-masing, tetapi tetap mengikuti struktur yang sudah ditentukan. Dalam pengambilan beban belajar untuk siswa peran guru PA sangat penting. Guru PA menjadi penghubung antara pihak kurikulum sekolah dengan siswa sehingga siswa mengetahui beban belajar yang harus dituntaskannya. Peran guru BK menjadi pendukung siswa agar mampu menuntaskan keseluruhan beban belajar, sehingga tidak sampai lulus melebihi 4 tahun.

\section{Penilaian, penentuan indeks prestasi dan kelulusan pada penyelenggaraan SKS di SMAN 2 Blitar}

Penilaian sesuai dengan pokok bahasan atau kompetensi dasar dengan skala angka 0 sampai 100. Penentuan indeks prestasi dengan cara beban belajar ditambah dengan seluruh mapel dibagi dengan jumlah beban belajar. Indeks prestasi ditentukan oleh grade yang diproses dari e-rapor melalui masukan nilai dari guru mata pelajaran. Kriteria kelulusan siswa ditentukan oleh Nilai Sekolah dan Nilai Sikap dengan pertimbangan rapat dewan guru. 


\section{PEMBAHASAN}

Hasil penelitian ini yaitu SMA Negeri 2 Blitar yang pertama adalah persyaratan penyelenggaraan di SMA Negeri 2 Blitar. Sekolah dikatakan mampu menjadi penyelenggara sistem kredit semester harus tergolong sebagai Sekolah Kategori Mandiri (SKM). Sehingga nantinya tidak terdapat kendala sepertiyang disampaikan oleh Rustika \& Zulkarnain (2016) Hasil penelitian menunjukkan bahwa implementasi Kurikulum 2013 dengan SKS sudah terlaksana dengan baik, namun belum terlaksana secara maksimal, terdapat faktor kekuatan dan kelemahan, terdapat faktor peluang dan tantangan, serta banyak dampak yang ditimbulkan dari implementasi Kurikulum 2013 dengan SKS di SMAN 1 Batu. Karakteristik SKM terdapat dukungan Internal dan eksternal. Dukungan internal meliputi kinerja sekolah, kurikulum sekolah, kesiapan sekolah, sumber daya manusia dan fasilitas sekolah.

SMA Negeri 2 Blitar mempunyai dukungan internal meliputi dari kinerja sekolah, kurikulum sekolah, kesiapan sekolah, Sumber Daya Manusia, dan fasilitas sekolah yang memadai. Kemudian terdapat dukungan eksternal dari beberapa pihak diluar sekolah seperti komite sekolah, dinas provinsi, orangtua siswa dan sebagainya. Hal itu dapat dibuktikan dengan dokumentasi. Sehingga SMA Negeri 2 dikatakan mampu dalam menyelenggarakan sistem kredit semester.

Komponen beban belajar dalam penyelenggaraan SKS di SMA Negeri 2 Blitar terdapat beberapa komponen yaitu kegiatan tatap muka, penugasan terstruktur dan kegiatan mandiri. Kegiatan tatap muka merupakan kegiatan pembelajaran seperti biasa dengan metode kelompok. Terdapat kelompok belajar cepat, sedang, dan lambat. Penugasan terstruktur dan kegiatan mandiri terangkum menjadi satu dalam Unit Kegiatan Belajar Mandiri (UKBM). Menurut Setyaningsih \& Harjito (2013) permasalahan yang muncul dalam pelaksanaan kurikulum Sistem Kredit Semester di SMA Negeri 3 Semarang yaitu kurangnya waktu bagi guru untuk menjelaskan materi dalam satu semester sehingga aspek psikomotor kurang diperhatikan.

Penentapan beban belajar pada penyelenggaraan SKS di SMA Negeri 2 Blitar dengan menyatakan satuan beban belajar menggunakan istilah jam pelajaran. Satu jam pelajaran sistem kredit semester adalah 45 menit dengan presentase tugas terstruktur dan kegiatan mandiri kurang dari $60 \%$ dari kegiatan tatap muka.

Penentuan penjurusan dilakukan di awal penerimaan siswa baru dengan ketentuan beban belajar dari kurikulum 2013. Hasil penelitian dari Rumahlatu dkk, (2016) menunjukkan bahwa siswa dan guru di Kabupaten Seram bagian barat siap menerapkan kurikulum 2013. Penentuan beban belajar maksimal dan minimal pada penyelenggaraan SKS di SMA Negeri 2 Blitar ditentukan oleh siswa sendiri dilihat dari kecepatan belajar masing-masing siswa.

Menurut Qurtubhi (2018) hasil penelitian belajar kelompok terjadi perbedaan antara "sebelum" dan "setelah" di kelas eksperimen yang diberikan perlakuan menunjukkan peningkatan yang signifikan. Dalam kelas kontrol antara "sebelum" dan "setelah" yang tidak diberi perlakuan ada juga perbedaan, tetapi bukan peningkatan tetapi penurunan. Siswa dalam kelompok belajar cepat dapat lulus lebih cepat seperti pada kelas akselerasi sebelum dicetuskan sistem kredit semester. Pembelajaran acelerasi didasarkan pada karya Georgi Lozanov, seorang medis Bulgaria dokter dan profesor psikiatri yang mengembangkan metode pengajaran yang dia sebut 'sugestopedia' (Ganiron, 2013).

Pembagian komposisi belajar pada penyelenggaraan SKS di SMA Negeri 2 Blitar menjadi 3 kelompok. Kelompok A terdapat 6 mata pelajaran. Kelompok B terdapat 3 mata pelajaran dan 1 muatan lokal. Kelompok $\mathrm{C}$ pada kelas X terdapat 6 mata pelajaran terdiri dari 4 mata pelajaran peminatan dan 2 lintas jurusan atau pendalaman minat. Kelompok C pada kelas XI dan XII terdapat 5 mata pelajaran terdiri dari 4 mata pelajaran peminatan dan 1 lintas jurusan atau pendalaman minat.

Pada tingkat kurikulum seluruh mata pelajaran setiap minggunya siswa harus menuntaskan 42 JP untuk kelas X, lalu untuk kelas XI dan XII harus 44 JP. Selanjutnya kriteria pengambilan beban belajar sangat bergantung pada guru Pembimbing Akademik dan guru Bimbingan Karir. Siswa dapat barganti jurusan ketika mendapat persetujuan dari orang tua, guru PA dan guru BK serta sanggup menuntaskan jam pelajaran yang sudah terlewat sebelumnya. 
Penilaian, penentuan indeks prestasi dan kelulusan ditentukan sesuai panduan SKS tahun 2017 dengan menjalankan panduan pada penyelenggarakan SKS di SMA Negeri 2 Blitar. Penilaian menggunakan skala angka 0 sampai 100 dengan penentuan grade berdasar abjad yang diproses oleh $e$ raport. Indeks prestasi juga sudah diproses oleh e-raport sehingga guru hanya memasukkan nilai dalam skala angka saja. Penentuan kelulusan mengacu pada nilai kognitif dan sikap.

Prayito (dalam Buchori \& Setyawati, 2015) menyatakan bahwa kecerdasan dan karakter yang baik pada siswa dapat ditingkatkan direhabilitasi dan direkonstruksi dalam proses pembelajaran dan membantu dengan e-learning. Kriteria siswa dinyatakan lulus adalah nilai sekolah lebih dari 7 dan nilai sikap baik. Selain dari kriteria tersebut siswa bisa lulus dengan pertimbangan rapat dewan guru.

\section{SIMPULAN}

Berdasar hasil penelitian persyaratan penyelenggaraan sistem kredit semester di SMA Negeri 2 Blitar telah terpenuhi dengan mendapat dukungan internal seperti kinerja sekolah, kurikulum sekolah, kesiapan sekolah, SDM sekolah dan fasilitas sekolah serta dukungan eksternal yang terdiri dari beberapa pihak di luar sekolah seperti komite sekolah, dinas provinsi, dukungan orang tua dan sebagainya. Komponen beban belajar dalam penyelenggaraan SKS di SMA Negeri 2 Blitar yaitu kegiatan tatap muka, penugasan terstruktur dan kegiatan mandiri. Penentapan beban belajar pada penyelenggaraan SKS di SMA Negeri 2 Blitar dengan menyatakan satuan beban belajar menggunakan istilah jam pelajaran setiap 45 menit dengan presentase tugas terstruktur dan kegiatan mandiri kurang dari $60 \%$ dari kegiatan tatap muka. Penentuan penjurusan dilakukan di awal penerimaan siswa baru dengan ketentuan beban belajar dari kurikulum 2013. Penentuan beban belajar maksimal dan minimal pada penyelenggaraan SKS di SMA Negeri 2 Blitar ditentukan oleh siswa sendiri dilihat dari kemampuan belajar siswa. Pembagian komposisi belajar pada penyelenggaraan SKS di SMA Negeri 2 Blitar menjadi 3 kelompok bergantung pada tingkat kelasnya. Kriteria pengambilan beban belajar sangat bergantung pada guru Pembimbing Akademik dan guru Bimbingan Karir. Penilaian, penentuan indeks prestasi dan kelulusan ditentukan sesuai panduan SKS tahun 2017 dengan menjalankan panduan pada penyelenggarakan SKS di SMA Negeri 2 Blitar.

\section{REFERENSI}

Apriliani, V., \& Made Suwanda, I. (2019). Implementasi Sistem Kredit Semester (SKS) Pada Mata Pelajaran PPKn di SMA Negeri 3 Sidoarjo. Kajian Moral dan Kewarganegaraan, 7(1). Retrieved from https://jurnalmahasiswa.unesa.ac.id/index.php/jurnal-pendidikan-kewarganegaraa/article/view/27667

Buchori, A., \& Setyawati, R. D. (2015). Development learning model of charactereducation through e-comic in elementary school. International Journal of Education and Research, 3(9), 369-386. Retrieved from http://ijern.com/journal/2015/September-2015/30.pdf

Makeleni, N. T., \& Sethusha, M. J. (2014). The experiences of foundation phase teachers in implementing the curriculum. Mediterranean Journal of Social Sciences, 5(2), 103.Retrieved from https://www.mcser.org/journal/index.php/mjss/article/view/1965

Muhamad, B., \& Saparahayuningsih, S. (2016). An attitude and character instructional development based on Curriculum 2013 in elementary school. Creative Education, 7(02), 269. Retrieved from https://file.scirp.org/pdf/CE_2016022414473561.pdf

Muhammedi, M. (2016). Perubahan Kurikulum di Indonesia: Studi Kritis Tentang Upaya Menemukan Kurikulum Pendidikan Islam yang Ideal. Raudhah, 4(1). Retrieved from http://jurnaltarbiyah.uinsu.ac.id/index.php/raudhah/article/download/61/40

Muhlis, A. (2017). Pengembangan Pembelajaran dengan Sistem Kredit Semester di MTs Negeri Sumber Bungur Pamekasan. Nuansa: Jurnal Penelitian Ilmu Sosial dan Keagamaan Islam, 14(1), 139-184. Retrieved from http://ejournal.stainpamekasan.ac.id/index.php/nuansa/article/download/1317/941 
Putri Pertiwi, Cahyaning. (2015). Analisis Penerapan Program Sistem Kredit Semester (SKS) Pada Pembelajaran Mata Pelajaran IPA di SMP Negeri 1 Sidoarjo. Pendidikan Sains, 3(03). Retrieved from http://jurnalmahasiswa.unesa.ac.id/index.php/pensa/article/view/13044

Qurtubhi, W. M. (2018). Effect Of Cooperative Learning Model Type Think Pair And Share (Tps) On Student Cooperation (Quasi Experiments on Social Studies Learning Class VII in 1 Cikajang Junior High School). International Journal Pedagogy of Social Studies, 2(2), 53-58.Retrieved from http://ejournal.upi.edu/index.php/pips/article/view/10165

Rostika, D., \& Zulkarnain, W. (2016). Analisis Implementasi Kurikulum 2013 Dengan Sistem Kredit Semester. Jurnal Manajemen Pendidikan, 25(2), 191-199...Retrieved from http://ap.fip.um.ac.id/wp-content/uploads/2017/01/JMP-Edisi-September-2016-vol-25-no-2-sep2016_p074-090.pdf

Rumahlatu, D., Huliselan, E. K., \& Takaria, J. (2016). An Analysis of the Readiness and Implementation of 2013 Curriculum in the West Part of Seram District, Maluku Province, Indonesia. International Journal of Environmental and Science Education, 11(12), 5662-5675. Retrieved from http://www.ijese.net/makale/731

Setyaningsih, Y. I., \& Harjito, H. (2013). Peningkatan Keterampilan Laboratorium Melalui Metode Praktis Demonstratif Pada Kurikulum Sistem Kredit Semester. Chemistry in Education, 2(2).Retrieved from http://journal.unnes.ac.id/sju/index.php/chemined/article/view/1492

So, K., \& Kang, J. (2014). Curriculum reform in Korea: Issues and challenges for twenty-first century learning. The Asia-Pacific Education Researcher, 23(4), 795-803. Retrieved from https://link.springer.com/article/10.1007/s40299-013-0161-2

Sugiyono, D. (2010). Metode penelitian kuantitatif kualitatif dan R\&D. xiii.

Sujiono, Y. N. (2010). Mengajar dengan portofolio. Jakarta: indeks.

Wahid, A. (2017). Penerapan Program Sistem Kredit Semester (SKS) Pendidikan Agama Islam di SMS Muhammadiyah 3 Jakarta. Jurnal Pendidikan Islam, 7(2), 21-37..Retrieved from https://journal.uhamka.ac.id/index.php/jpi/article/view/176

Wanda Febriya, Rezki. (2014). Survei tentang persepsi dan kesiapan konselor terhadap bimbingan dan konseling berdasarkan kurikulum 2013 di SMA Surabaya Selatan. Jurnal BK UNESA, 4(3).Retrieved from https://jurnalmahasiswa.unesa.ac.id/index.php/jurnal-bk-unesa/article/view/9199

Widyastono, H. (2013). Alternatif Program Pendidikan bagi Peserta Didik SMA yang Memiliki Kecerdasan Istimewa. Jurnal Pendidikan dan Kebudayaan, 19(4), 594-607..Retrived from http://jurnaldikbud.kemdikbud.go.id/index.php/jpnk/article/view/312 